\title{
Challenges for integrating bicycles and public transport in Brazilian metropolitan regions
}

\author{
M. S. G. Tobias ${ }^{1}$, M. L. A. Maia ${ }^{2}$ \& I. M. D. Pinto ${ }^{3}$ \\ ${ }^{1}$ Federal University of Para, Brazil \\ ${ }^{2}$ Federal University of Pernambuco, Brazil \\ ${ }^{3}$ Federal University of Bahia, Brazil
}

\begin{abstract}
In recent decades, several studies and actions have been highlighted in search of "aggregation" or consolidation of demand through modal integration, primarily driven by operational objectives and participation of non-motorized modes in relation to the number of trips produced. In this paper the possibilities for integrating bicycles and public transport in Brazilian metropolitan regions were explored, with cases under study in Belem, Recife and Salvador. The method is empirical, based on secondary data involving the urban transport network and information from the users' perception and the integration. So the central questions of this study are: Why integrate? Who integrates? How to integrate? The space-based data are based primarily on the dimensions analysis, besides the consideration of the strategic importance of the potential points of integration. There were three kinds of surveys: household survey - Recife; users' survey (in the stations) and cyclists on the road survey - Belem and Salvador. The focus group concerns the demand under study, with the focus of this work on cyclists using the bike for a range of activities, present in the public transport network, and whether or not they use the bus as a mode of public transport. The answers to central questions come from analysis of the dimensions above, a recursive process of analyzing results aimed at understanding the issues and the definition of the aspects of integration. In general, the central questions were answered and the method showed itself as suitable for such studies on integration in public transport.
\end{abstract}

Keywords: methodology, cycling systems, integration, public transport, metropolis. 


\section{Introduction}

Metropolitan regions of Brazil have suffered an increasing loss of demand for public transport, therefore, private transport has been more used, especially the motorized kind, jamming the traffic of locations and increasing the number of accidents and detriments. Some data shows that allied to the income reduction, the lack of quality of the bus services contributed in decreasing the number of people using them. At the same time, little is known about the increase in the use of non motorized transport, in particular cycling, in metropolitan Brazilian cities, neither potentially the people's willingness to use them for short to medium trips or as a feeder to public transport. This work aims to unveil what are the most important attributes for cyclists and how feasible is it to promote the integration of bicycles to the public transport network in three metropolitan cities located, one in the north and two others in the northeast of Brazil. The main research questions were: Why integrate? Who integrates? How to integrate? The case studies were undertaken in the metropolitan regions of Belem, Recife and Salvador, with 2 million, 3 million and 3.5 million inhabitants, respectively (see Figure 1). Further, mobility indicators will be shown which can subsidize several decisions regarding investments in the sector.

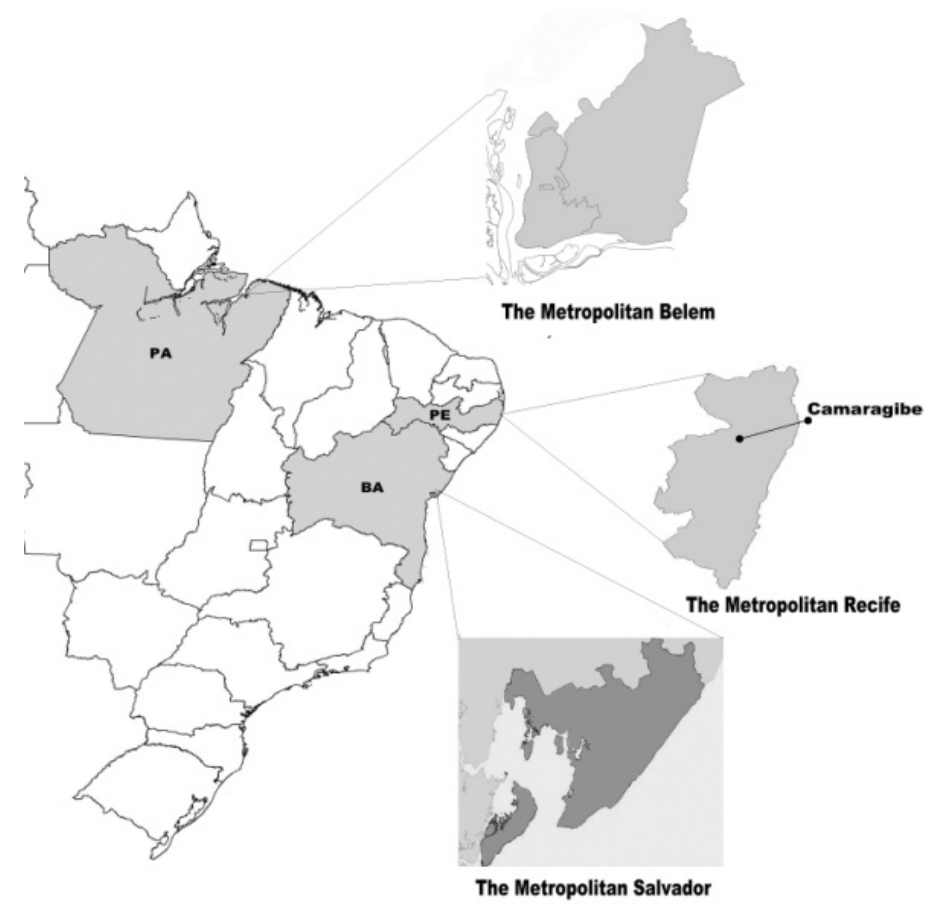

Figure 1: $\quad$ Metropolitan Belem, Recife and Salvador - the studied areas. 


\section{Theoretical framework}

Nowadays, because of traffic problems in cities, the possibility of cycling as an alternative urban transport is a really important matter for the government and population, and raises a great debate on sustainable urban mobility in which the benefits that non-motorized travel would bring to the community, such as congestion reduction, health promotion, ultimately the quality of life improvement, are highlighted. In addition, the bike is known as a means of cheap transportation is often recommended for exercise, ecological, pollution-free atmosphere or noise - improving the quality of the environment and promoting public health. Among the solutions designed for urban transport is the integration of public transport with the individual modes of transport, in particular the nonmotorized, in the case of walking and bicycles. The alternatives of integration have been the main challenge of modern urban transport.

In recent decades, several studies and actions have been highlighted in the search for "aggregation" or consolidation of demand through modal integration, primarily driven by operational objectives [1]: i) reduce the number of trips; ii) increase the participation of non-motorized modes in relation to the number of trips produced; and iii) reduce travel distances and increase vehicle occupancy levels, the number of motorized trips produced, promoting the use of public transport, for instance. In practice, modal integration challenges are centered on the following principles of sustainability [2]: i) the care the individual needs to obtain advances in social inclusion; ii) the effective protection of the environment, iii) the rational use of natural resources; and iv) the maintenance of high levels of economic development and employment. Among the aspects that can influence travel demand, it has been crucial to the built environment that, according to Cervero and Kockelman [1], three dimensions can influence: density, diversity and design. These dimensions may not only affect travel demand, but also the routes and modes of transport.

The density scale is commonly treated as the intensity of population, jobs and trade activities and services in a given space, as a potential indicator of trip generation. The size diversity has indicators of demand associated with proximity to the most diverse destinations, with studies focused on suburban shopping centers [3, 4] and, the design dimension associated with the characteristics of the road, traffic and environment.

The potential of integration in transportation planning is presented through the various aspects, including measures involving improvements in infrastructure, operational management and pricing, and the integration involving the various modes available in the area in question. To integrate urban transport requires essential investments, innovations and changes in operating systems installed. In the case of cycling with public transport, the integration has two main objectives: i) the inclusion of bicycle as the usual mode of transport in urban travel and; ii) to strengthen the collective modes as the main means of transport for medium and long travel distances of the people in medium and large human settlements. 
A good conditioning of the integrated transport system requires special attention from the government in order to approach the bicycle from the terminals and places of high demand such as subways, trains, barges, boats, ferries, road and urban buses, allowing the recovery of the collective modes and expansion of the radius action of cyclists in cities and regional areas. This can be accomplished by creating bike parking in what, for example, can be billed as full-time or, in other situations, being the bike on board of transport. The most common ways of integration of the bicycle to public transport in urban areas are:

- Integration of bicycles - buses: is one of the most important alternatives for integration - the bicycle and bus. Brazilian cities are increasing government initiatives to encourage the use of the bicycle with the bus. Following the examples of some countries in Europe in the 90s being pioneers in developing projects for the integration of these systems in their cities. However, a lack of parking lots for bicycles and integration with the bus is still a recent idea in Brazil and is currently undergoing research on the feasibility and testing phases in some cities. In Brazil, in transport corridors, the presence of spontaneous integration is usual, with bicycles parked in various places, where the cyclist can leave them and take public transport.

- Integration of bicycles - trains: is another important way of integration, especially in big cities. In Brazil, there is integration of the bicycle to the train in some cities like Rio de Janeiro, Porto Alegre and Sao Paulo. In the operation of these systems there are some operational measures that make the service more effective: i) sheets for access control; ii) numbering of "streets" and parking spaces; iii) mechanical assistance; iv) bikes offering assistance to members, in case of failure with their bikes; v) covered parking for older members and; providing education to cyclists on conduct inside and outside parking.

- Integration bicycles - subway: is the greatest potential for integration of large population centers. In some European countries, this integration system is vital for the promotion of urban mobility, such as in Amsterdam and Copenhagen, where the government and private enterprise are always looking for improvements to cyclists, encouraging more sustainable mobility. In Brazil, cities like Rio de Janeiro and Sao Paulo are increasingly investing in accessibility for cyclists at stations with well-structured and low-priced bike parking. In some cases, on weekends and holidays, cyclists still have the alternative of carrying their bikes along with a few wagons. Brasilia, Salvador, Fortaleza and Belo Horizonte, also have subway lines and favorable conditions for the integration between the two modes.

- Integration of bicycles and boats or ferries: because it is a continental country and has a gigantic hydro capacity, Brazil has the possibility of integration of the bicycle to fluvial and sea transport. This is the case of Santos and Guaruja, on the coast of Sao Paulo, with tariff exemption for cyclists on board of the ferry crossing. The north of Brazil, which has the largest watershed in the world, with potential for integration of the bicycle with fluvial and road transport, bicycles being used in boats and ferries is quite common, as in the case of crossing from Belem to Marajo Island. 
Given the above, this paper explores the conditions and the current cyclist's profile demand able to adopt the system of integrating bicycle and public transportation, as an aid to decision making by the government in implementing cycling projects. To this end, it employs a research methodology that combines different ways of surveys, depending on the situation and available information to obtain the desired frame answers to the questions listed above.

\section{Methodology}

A complete characterization of the urban transport system of a city requires surveys: a survey of the general characteristics of the city and the urban public transport system, lines, stations and terminals which are controlled by schedules, operational programming of lines, accessibility to public transport; bus stops and stations (terminals), the situation of the fleet, the road system, and surveys that provide information about the safety of transport, the performance of operating personnel, the productivity and service quality fleet maintenance, etc. Each type of survey corresponding to one or more needs information about the system and its users. Depending on what is desired from the system, the types of surveys required are established. In this study, surveys were carried out for general characterization of each city and the urban transport system, from the literature review of institutional documents, maps, reports containing information about the occupation and land use, transportation, geography, topography, economy. For cyclists, the opinion survey was used, which is recommended on many occasions in order to get feedback from users on issues related to the quality of transport, price, or even to collect suggestions on a specific issue or in general. The opinion survey can be conducted at the bus stop, in public transport (on board), inside the stations (terminals), on the streets or in households.

The method applied is empirical, based on secondary data about the urban transport network and on primary data information about users' socioeconomic profile and their perception about integration. The target population researched for case studies in metropolitan Belem and Salvador were primarily cyclists who use bicycles for a range of activities, in the public transport network; they may only use a bicycle, or may even be a user of public transport as well. The Belem survey was conducted in the public transport network and surrounding areas of fairs and ports, with the cyclists taking trips on the route of the buses. In the case of Salvador cyclists were at the multimodal stations or in their surrounding areas and; in the case of Camaragibe, Great Recife, the research was based on a household survey and the population sampled were aged over 15 years, who were able to ride a bike, but not necessarily used it as a mode of transport. The space-based data was based primarily on the Cervero and Kockelman dimensions analysis [1], besides the consideration of the strategic importance of the potential points of integration, such as factors associated with significant flow; favorable conditions around the modes to be integrated; the existence of spontaneous integration and; also ways to make integration viable.

The Belem Metropolitan Region, in the northern region of Brazil, is known as the gateway to the Amazon with a population of 2 million [5] and is also part of 
a metropolitan region that includes four municipalities comprising $1800 \mathrm{~km}^{2}$. Belem is located on a peninsula at Guajara bay, and comprises two sectors: the continent and the islands (see Figure 1). The urban transport system consists of buses, minibuses, taxis, boats, vans and mototaxis. The system of public transportation by bus is predominant and there are 162 lines of conventional service, carrying an average of 1 million passengers daily. The fleet is 1700 vehicles making 14,000 trips per day. The city already has some cycling projects. Origin-destination matrix, 10 years ago [6], presented a percentage of $51.1 \%$ of households with bicycles and modal share of trips by bicycle in $6 \%$ of urban trips. At that time the urban population of Belem was 1.5 million, $25 \%$ less than the current population. Since then, it has been observed that the flow of cyclists is ever increasing in urban areas.

For interviews, there was a pre-selection of points of convergence of flows of strategic movement of bicycles, either through traffic or local (fairs and ports). At these points counts were made on weekdays and weekends, the peak morning and afternoon peak, assuming a peak flow greater than 1000 bicycles at the peak in all the days of collection, twelve points were obtained as the most relevant stream of cyclists. Adopting a binomial probability sample, with $95 \%$ confidence and $10 \%$ error, in the twelve selected points interviews were conducted using a questionnaire covering socio-economic data, travel patterns and opinions about cycling and the bus and, finally, on the integrated use of the bicycle with the bus and the corresponding infrastructure. There were about 1,152 cyclists interviewed.

The Salvador Metropolitan Region, located in the northeast of Brazil, is composed of two geographically distinct areas - the mainland and islands (see Figure 1). By land, it borders three municipalities and, by sea, through the Todos os Santos Bay and Aratu Bay, it limits the six municipalities. The population exceeds 3.5 millions [5] and the urban sprawl occurred initially in the flat tops of the hills and, from the twentieth century, began to extend more fully to the slopes and bottom of the valleys, with the deployment of new road systems.

The urban transport of Salvador is composed traditionally of rail, with trains, barge, barges and ferries, roads, buses, minibuses, taxis and vans. Among the modes of urban transport, buses are the most used, with a fleet of 2500 vehicles. Research developed by the Municipal Urban Transport in 1995 showed that the bus is the most used (52\%), followed by the journey on foot with $29 \%$ of trips undertaken. It was also seen that the bike had a percentage higher than the train and barge, however, it is the only mode not seen in the transportation plan of Salvador. Since 2004, with the Master Plan for Urban Development in Salvador, actions have been developed to promote and prioritize the use of bicycles in the city, but are still disconnected and do not constitute a comprehensive policy to promote cycling to complement the displacements from urban public transportation.

The survey was conducted in three multimodal stations: (Lapa, Calçada and Mussurunga), over two weeks, where there is integration among buses, trains and subways. Also, interviews were conducted in areas surrounding the stations. There were 89 interviewees in the three stations and 305 in surrounding areas. 
The survey consisted of a direct approach to the interview by completing questionnaires, involving socioeconomic, travel patterns, evaluation of service quality attributes and beliefs about the integration of the bicycle with public transport modes, as well as facilitators and barriers to this.

The Metropolitan Recife, located in the northeast of Brazil, is composed of 14 municipalities, has 3.3 million inhabitants and comprises $2800 \mathrm{~km}^{2}$ (see Figure 1). Camaragibe is the municipality in the north of the Metropolitan Recife and has 144,506 inhabitants [5]. The urban transport system comprises metro lines (over ground), buses, minibuses, taxis, vans and mototaxis. The Recife metro and buses form part of the Integrated Structural System (SEI), which comprises 7 terminals and 49 bus lines and covers the whole metropolitan region of Recife. It contains both radial and perimeter lines. At the intersections of these axes there are terminals for connections allowing the passengers to change lines without paying a second fare. The research was based on the argument that the implementation of bicycle parking areas at metro stations would facilitate bicycle-train integration, increase the power of attraction of public transport for the people living in the surrounding area of these terminals, and improve accessibility to the stations. Its main objectives were to determine the cycling potential around the metro station, proposing the use of bicycles as a feeder mode of these systems and encouraging bike-train intermodality. The empirical study was made in the neighborhoods surrounding Camaragibe Station which is the fourth most important metro station in terms of numbers of daily passengers $(20,000)$ in the metro system. SEI is also important for those who live in the western zone of great Recife.

The methodology consisted of a household survey, where the probability method of cluster sampling SAS was used, in two stages, in the area located in a radius of between 500 and 1000 meters around the axis of the metro station. The first stage was random sampling of the streets to be covered (14 out of 74 were randomly selected) and the second one referred to the households to be surveyed (72 out of 361). The research worked with a 95\% confidence level. 101 questionnaires were applied with the householders over 15 years old who were able to ride a bike.

\section{Results}

The results are focused on the profile of people who want or are willing to integrate; the reasons for integration; and also how to integrate, specifying important system components for this to happen and, finally, the challenges for integration. Considering the cases described, it was evident that the participation of cyclists in the public transport system contributes to reducing traffic conflicts in the corridors of public transportation and to promote social inclusion through transport. Furthermore, the implementation of parking facilities for bikes is an important lever to the integration between bike-public transport modes as well as being a way to stimulate the use of public transport. 


\subsection{Belem results}

- Socioeconomic profile: it has shown that the relationship between age and income of cyclists, especially the presence of most cyclists in the first income ranges, but also the fact that in the age group of cyclists who have up to 1 minimum wage/month (in Brazil, about \$345) is the predominance of young cyclists. Also, that the predominance of cyclists is men, especially on higher incomes and with absolute majority in all areas: in lower incomes, proportionality between men and women approaching, especially in the area of the periphery of Belem, and focuses on the income of one minimum wage.

- Travel patterns: the transportation network in Belem is concentrated and the macro accessibility significantly compromised by the lack of a paved road system, the middle and long travel distance by bicycle culminates in sharing the physical bus transportation in major transportation corridors in the region. There is the effective use of the bicycle for work activities in all urban areas and has an average cyclists effecting trips between 20 to 30 minutes in the Central and Middle areas and as it approaches an area of expansion, the travel time increases to more than 30 minutes. Regarding the use of public transport, $63 \%$ of cyclists said they were users of the bus and the access mode is predominantly on foot or by bicycle. Furthermore, 78\% of cyclists interviewed agreed that having a bike rack near a bus stop would be important or very important.

- About integration: the field survey showed that $90 \%$ of cyclists felt it was important or very important to integrate the bike with the bus and that $70 \%$ would be willing to pay to keep the bike. The most important attributes of a bike parking would be covered and free. The results indicated a demand to predominantly young and male cyclists, on low income, who use the bike, mainly for work. The greatest potential was observed in the expansion area, where travel outside of this area is so important and lasts an average of over 30 minutes, which characterize the group of interest for integration with the bus. Also, was identified the willingness of the cyclist in integration, since there is infrastructure to park the bike and the cost is affordable. A survey of volumetric counting found a demand of 4,000 cyclists who travel at peak times the area of expansion for the area and Central Middle. Considering internal and external travel within the areas studied, 28485 cyclists were counted at peak times in the twelve points investigated.

\subsection{Salvador results}

- Socioeconomic profile: in the stations, there was equilibrium between male and female cyclists and the predominance of cyclists in the first income ranges $(53.6 \%)$. Also, the age is between 18 and 35 years old (approximately, 50\%). Around the stations, the cyclists are male by an absolute majority with a predominance of young cyclists. The income is concentrated up to 1 to 3 Brazilian minimum wages per month. 
- Travel patterns: in the three stations the majority of cyclists claimed to know cycling (on average $77.7 \%$ ), however, did not use the bike any day per week, or rarely. When using the bike, the main purpose of the trip is leisure. Among the reasons related to little use of bicycle are just as the main: the dangerous traffic (on average 26\%) and inadequate pavement (on average $25.3 \%$ ). As for travel times, the majority of cyclists spend over 30 minutes (on average $31.5 \%$ ). Out of the stations, the situation changes dramatically: most cyclists use the bicycle every day of the week (on average $73 \%$ ) and due to work. The travel times vary in the regions, but most cyclists said they spend over 30 minutes per trip (44.6\%). Among the advantages in using the bicycle: agility $(12 \%)$; for health $(17.1 \%)$ and the practice of physical exercise $(16.9 \%)$. The majority of cyclists interviewed had never used the bike and left the nearby stations (on average $72 \%$ ) due to reasons such as insecurity and lack of public parking.

- About integration: in the stations, most of the interviewees would use the bicycle as a mode of transport, making integration if there were parking lots for bicycles (on average 78.6\%) and that parking should be secure (on average $30 \%$ ), be covered (on average $21 \%$ ) and are situated within or near the station (on average 18\%). The users were willing to pay for use of the bicycle (on average 84\%) since the price was affordable. Out of stations, proportionately, the intention of the interviewees in using the bike integrated with public transport remained equal to the interviewees in the stations. Also, the same conditions remained, however, willingness to pay decreased.

\subsection{Recife results}

- As a general result, it is possible to consider that bicycles can work as an important feeder of the transport system and can be used mainly for short distance-micro accessibility to bus/metro stations, working as complementary transport systems and services. The empirical evidence shows that there is potential for cycling in the area researched, according to the socio economic background of the population and the flat topography predominantly in the region. The willingness of the population researched to make trips by bicycle as a means of integrating with the public motorized transport system (bus and metro) in the terminal was also observed.

- The socio economic backgrounds of the population are similar to those observed in other research. About $80 \%$ of the individuals receive up to 2 Brazilian minimum wages per month. Workers and students are $76 \%$ of the population and are the ones who more frequently cycle to their daily activities. In addition, $83 \%$ of the population researched made trips by metro or by bus to their daily activities using the Integrated Structural System. Among them, 58\% reach the integrated terminal (bus/metro) traveling by bus and $33 \%$ by walking. It is possible to argue that these trips could easily be made by bicycle, once the survey was undertaken in an area between $500 \mathrm{~m}$ to $1 \mathrm{~km}$ from the terminal. The majority of the population surveyed $(63 \%)$ does not cycle even though they are able to ride a bike. 
- Asked about the barriers to cycling to the terminal, the most important aspect mentioned was the lack of parking facilities. For $65 \%$ of the population surveyed this facility would stimulate trips made by bike to the station. Aspects relating to security, climate conditions, topography and public lighting were not considered as relevant. Risks of accidents were a relevant barrier especially to those who never travel by bike. Concerning the features and services provided in the parking area, 37\% would prefer they were located inside the metro station, $36 \%$ prefer sheltered parking, $28 \%$ for it to be free of charge. It is important that $27 \%$ of the population has never cycled to the terminal because they do not own a bike.

\section{Conclusions}

In general, the challenges for integrating bicycle and public transport in Brazilian Metropolitan Regions depends on better planning and public investment in the system as part of a policy of urban mobility in transportation. In Belem, the results pointed to the implementation of bicycle parking in strategic integration of the physical desires of cyclists traveling with public transport and road treatment with bike lanes for complementation. For the income of the population involved, one could think of public bicycle parking, free or charged, or subsidized in the periphery to encourage bicycle use as a complementary way to the bus. In Salvador, both public transport users and cyclists said they would use the bicycle as a way of integration with the stations if there were bike parking. Although many of the cyclists pointed to the economic aspect as the main factor influencing the use of bicycles, in both cases, most of the interviewees had never used in stations or rode a bicycle due to the dangerous traffic problem. In the case of Camaragibe, Greater Recife, the results show that there is a strong evidence of cyclist potential for bike-metro integration, considering the socioeconomic profile of the area and the environmental conditions which are favorable to the intermodality to occur. It was evident that bicycle parking areas at metro stations directly influence the decisions of choice for transport modes for the residents living in the vicinity. It is important to note that some measures need to be taken so as to promote cycling and, its integration as a feeder mode to the public transport system. The most frequent requests by the population are: (i) the provision of sheltered parking facilities, inside the terminal, safe and preferably free of charge; (ii) traffic calming measures around the terminal providing a safer environment for cyclists; (iii) financial support for the acquisition of bikes. These provisions would probably improve the attraction to public transport for the people living in the surrounding areas of these terminals and their accessibility.

\section{References}

[1] Cervero, R. and Kockelman, K., Travel demand and the 3D's: density, diversity and design. Transportation Research Part D, 2 (3), p. 199-219, 1997. 
[2] Banister, D., The sustainable mobility paradigm. Transport Policy, 15, $\mathrm{p}$. 73-80, 2008.

[3] Cervero, R., Jobs-housing balancing revisited. Journal of the American Planning Association, 62 (4), p. 492-511, 1989.

[4] Frank, L. D. and Pivo, P., Impacts of mixed use and density on utilization of three modes of travel: single-occupant vehicle, transit and walking. Transportation Research Record, 1466, p. 44-52, 1994.

[5] BRASIL, Censo demográfico - população residente. Instituto Brasileiro de Geografia e Estatística, Rio de Janeiro, 2010.

[6] JICA, Agência de Cooperação Internacional do Japão, Plano Diretor de Transportes Urbanos. Região Metropolitana de Belém. Belém, JICA/COHAB, 2001. Relatório Final.[8] SEPLAN/ PDDU - Secretaria Municipal de Planejamento de Salvador. Plano Diretor de Desenvolvimento Urbano de Salvador. Minuta de Lei. Prefeitura Municipal de Salvador, 2004. 